\title{
Equivalent Outcomes in Patients with Chronic Myelogenous Leukemia after Early Transplantation of Phenotypically Matched Bone Marrow from Related or Unrelated Donors
}

\author{
Stella M. Davies, MB, BS, PhD, Todd E. DeFor, MS, Phillip B McGlave, MD, \\ Jeffrey S. Miller, MD, Catherine M. Verfaillie, MD, John E. Wagner, MD, Daniel J. Weisdorf, MD
}

PURPOSE: To determine if the favorable outcomes after transplantation of matched sibling donor bone marrow in patients with chronic myelogenous leukemia can be achieved using bone marrow from an HLA-A,B/DRB1-matched unrelated donor.

SUBJECTS AND METHODS: Between April 1983 and December 1997, 141 patients with chronic myelogenous leukemia in its first chronic phase received a bone marrow transplant from a matched sibling donor $(\mathrm{n}=96)$ or an HLA-A,B/DRB1matched unrelated donor $(n=45)$. The median age of matched sibling donor recipients was 38 years (range, 8 to 56 years) and of unrelated donor recipients was 35 years (range, 3 to 53 years; $P=0.03$ ). The median follow-up was 6 years (range, 1 to 15 years) in matched sibling donor recipients and 5 years (range, 2 to 10 years) in unrelated donor recipients.

RESULTS: There was no significant difference in the 5-year survival rates of matched sibling donor recipients [58\%; 95\% confidence interval (CI), 48\% to 68\%] and unrelated donor recipients $(53 \%$; $95 \% \mathrm{CI}, 39 \%$ to $67 \% ; P=0.4)$. Among patients who underwent transplantation within 1 year after diagnosis, the 5-year survival rate of matched sibling donor recipients (76\%; 95\% CI, 65\% to 87\%) was not significantly different $(P=0.5)$ from that of unrelated donor recipients $(70 \% ; 95 \%$ CI, $52 \%$ to $88 \%$ ). In multiple regression analysis, longer time from diagnosis to transplantation, T-cell depletion, and grades III or IV graft versus host disease were independently associated with poorer survival. Transplantation of unrelated donor bone marrow was not associated with mortality (relative risk, 1.1; 95\% CI, 0.6 to $2.1 ; P=0.7$ ).

CONCLUSIONS: Transplantation of bone marrow from a matched sibling donor or an HLA-A,B/DRB1-matched unrelated donor produces equivalent outcomes in patients with chronic myelogenous leukemia, particularly if the transplant takes place within 1 year after diagnosis. Am J Med. 2001;110: 339-346. (C) 2001 by Excerpta Medica, Inc.
B one marrow transplantation is an effective treatment for chronic myelogenous leukemia. It is the preferred treatment for younger patients with an HLA-matched sibling donor (1-3). Among patients who undergo transplantation early in the chronic phase of the disease, the survival rate is approximately $70 \%$. However, most potential bone marrow transplant recipients do not have a matched sibling donor, and the use of phenotypically matched unrelated donor bone marrow for transplantation is increasing $(4,5)$. In initial reports, transplantation from an unrelated donor was associated with greater morbidity—including more frequent graft versus host disease, graft failure, and delayed immune reconstitution leading to late infections-and mortality than transplantation from a sibling donor (6-8).

From the Blood and Marrow Transplant Program, University of Minnesota, Minneapolis, Minnesota.

Supported in part by Grant CA65493 from the National Institutes of Health, Bethesda, Maryland, and by the Children's Cancer Research Fund and Bone Marrow Transplant Fund.

Requests for reprints should be addressed to S. M. Davies, MB, BS, $\mathrm{PhD}$, MMC 422 Mayo, University of Minnesota, Minneapolis, Minnesota 55455.

Manuscript submitted July 27, 2000, and accepted December 19, 2000.
Alternatives to bone marrow transplantation for chronic myelogenous leukemia include alkylating agents, such as busulfan and hydroxyurea, which control symptoms but generally do not prolong survival $(9-13)$. The effectiveness of interferon-alpha in extending survival is controversial. Administered early and in sufficient doses, interferon-alpha prolongs survival only in the minority of patients who experience a major or complete cytogenetic response $(14,15)$. However, toxicity can be dose limiting, and an extended interferon trial may adversely affect the outcome of subsequent allogeneic bone marrow transplantation. Although early reports described no adverse effect of prior interferon therapy (16), recent data suggest that such treatment worsens the outcome $(17,18)$.

Information on the likely outcome of bone marrow transplantation is essential for appropriate counseling of patients on therapeutic options. In this study, we sought to determine whether the excellent outcomes after transplantation of matched sibling donor bone marrow can also be achieved with bone marrow from unrelated donors. Because donor lymphocyte infusions can produce durable remissions with full donor chimerism after relapse of chronic myelogenous leukemia, we analyzed both survival and disease-free survival. 
Table 1. Characteristics of Patients Receiving a Bone Marrow Transplant for Chronic Myelogenous Leukemia

\begin{tabular}{|c|c|c|c|c|}
\hline & \multicolumn{3}{|c|}{ HLA-matched Donors } & \multirow[b]{2}{*}{$\begin{array}{c}P \\
\text { Value }\end{array}$} \\
\hline & $\begin{array}{l}\text { Sibling } \\
(\mathrm{n}=96)\end{array}$ & $\begin{array}{l}\text { Unrelated } \\
(\mathrm{n}=45)\end{array}$ & $\begin{array}{c}\text { Total } \\
(\mathrm{n}=141)\end{array}$ & \\
\hline & \multicolumn{3}{|c|}{ Number (Percent) or Median (Range) } & \\
\hline \multicolumn{5}{|l|}{ Recipient age } \\
\hline$<18$ years & $4(4)$ & $6(13)$ & $10(7)$ & 0.07 \\
\hline 18 to 34 years & $32(33)$ & $18(40)$ & $50(35)$ & \\
\hline$\geq 35$ years & $60(63)$ & $21(47)$ & $81(57)$ & \\
\hline Age (years) & $38(8$ to 56$)$ & 35 (3 to 53$)$ & 37 (3 to 56$)$ & 0.03 \\
\hline \multicolumn{5}{|l|}{ Year of transplant } \\
\hline 1980 to 1984 & $6(6)$ & 0 & $6(4)$ & \\
\hline 1985 to 1989 & $28(29)$ & $2(4)$ & $30(21)$ & \\
\hline 1990 to 1994 & $43(45)$ & $19(42)$ & $62(44)$ & \\
\hline 1995 to 1997 & $19(20)$ & $24(53)$ & $43(31)$ & \\
\hline \multicolumn{5}{|l|}{ Recipient/donor sex } \\
\hline Female/female & $17(18)$ & $8(18)$ & $25(18)$ & 0.4 \\
\hline Female/male & $32(33)$ & $9(20)$ & $41(29)$ & \\
\hline Male/female & $20(21)$ & $13(29)$ & $33(24)$ & \\
\hline Male/male & $27(28)$ & $15(33)$ & $42(30)$ & \\
\hline \multicolumn{5}{|l|}{$\begin{array}{l}\text { Recipient/donor cytomegalovirus } \\
\text { serostatus }\end{array}$} \\
\hline Positive/positive & $32(33)$ & $5(12)$ & $37(27)$ & 0.05 \\
\hline Positive/negative & $20(21)$ & $10(23)$ & $30(22)$ & \\
\hline Negative/positive & $10(10)$ & $8(19)$ & $18(13)$ & \\
\hline Negative/negative & $34(35)$ & $20(47)$ & $54(39)$ & \\
\hline Missing & 0 & 2 & 2 & \\
\hline \multicolumn{5}{|l|}{ Graft versus host disease prophylaxis } \\
\hline No T-cell depletion & $88(92)$ & $30(67)$ & $118(84)$ & 0.001 \\
\hline T-cell depletion & $8(8)$ & $15(33)$ & $23(16)$ & \\
\hline \multicolumn{5}{|l|}{ Preparative regimen } \\
\hline $\begin{array}{l}\text { Cyclophosphamide/total body } \\
\text { irradiation }(1,320 \mathrm{cGy})\end{array}$ & $90(94)$ & $44(98)$ & $134(95)$ & 0.08 \\
\hline Busulfan $/{ }^{*}$ cyclophosphamide & 0 & $1(2)$ & $1(2)$ & \\
\hline $\begin{array}{l}{ }^{*} \text { Cyclophosphamide } /{ }^{\dagger} \mathrm{VP} 16 / \text { total } \\
\text { body irradiation }[850 \mathrm{cGy}(1)]\end{array}$ & $6(6)$ & 0 & $6(4)$ & \\
\hline \multicolumn{5}{|l|}{ Time from diagnosis to transplant } \\
\hline$<1$ year & $63(66)$ & $27(60)$ & $90(64)$ & 0.13 \\
\hline 1 to 2 years & $25(26)$ & $9(20)$ & $34(24)$ & \\
\hline$>2$ years & $8(8)$ & $9(20)$ & $17(12)$ & \\
\hline Months & $8(3$ to 82$)$ & $10(5$ to 66$)$ & $8(3$ to 82$)$ & 0.03 \\
\hline Number of marrow cells $\left(10^{8} / \mathrm{kg}\right)$ & $2.0(0.4$ to 2.3$)$ & $2.0(0.1$ to 4.2$)$ & $2.0(0.1$ to 4.2$)$ & 0.09 \\
\hline
\end{tabular}

\section{PATIENTS AND METHODS}

Between April 1983 and December 1997, 141 consecutive patients with chronic myelogenous leukemia in its first chronic phase underwent bone marrow transplantation at the University of Minnesota, 96 from HLA-matched sibling donors and 45 from a phenotypically matched unrelated donor. The median age was 38 years (range, 8 to 56 years) in recipients of sibling marrow and 35 years (range, 3 to 56 years) in recipients of unrelated donor marrow (Table 1). The median follow-up was 6 years (range, 1 to 15 years) among matched sibling donor recipients and 5 years (range, 2 to 10 years) among unrelated donor recipients. Clinical and laboratory data were retrieved from the University of Minnesota Bone Marrow Transplant Database. Because detailed information on pretransplant therapy with interferon was not available for all patients, this information was not included in the 
analysis. All patients or their guardians signed informed consent documents approved by the Committee on the Use of Human Subjects in Research at the University of Minnesota.

\section{Unrelated Donor Selection}

Unrelated donors were located through national and international bone marrow donor registries (19). HLA-A and $-B$ typing was performed with serologic techniques that identified all specificities recognized by the World Health Organization at the time of transplant. All donorrecipient pairs were typed for DR by high-resolution DNA techniques, either prospectively or retrospectively. Unrelated donor recipients were included in the study only if they were HLA-A,B/DRB1 matched with their donors.

\section{Pretransplant Conditioning Therapy and Graft versus Host Disease Prophylaxis}

Most patients (94\%) received cyclophosphamide (120 $\mathrm{mg} / \mathrm{kg})$ and total body irradiation $(1,320 \mathrm{cGy}$ in 8 fractions) before bone marrow infusion (Table 1). One patient who had previously undergone radiation therapy received busulfan and cyclophosphamide, and 6 patients receiving T-cell-directed immunotoxin received cyclophosphamide, VP16, and single-fraction total body irradiation. As part of experimental protocols for graft versus host disease prophylaxis, marrow was depleted of $\mathrm{T}$ cells by elutriation in 33\% of unrelated donor recipients and by T-cell-directed immunotoxin in $8 \%$ of matched sibling donor recipients $(P=0.001)(20,21)$.

\section{Supportive Care}

Patients were hospitalized in single rooms with high-efficiency particulate air filtration. Patients routinely received prophylaxis with trimethoprim-sulfamethoxazole; at the onset of fever, patients were treated empirically with broad-spectrum antibacterial and antifungal agents. Patients who were seronegative for cytomegalovirus received blood products from seronegative donors or blood products that had been filtered to remove contaminating leukocytes. Acyclovir was administered prophylactically to patients who were seropositive for cytomegalovirus (10 mg/kg intravenously every 8 hours) or herpes simplex virus $(5 \mathrm{mg} / \mathrm{kg}$ intravenously every 8 hours). Patients who received a transplant after 1996 were monitored weekly for cytomegalovirus antigenemia until day 100 and treated with ganciclovir if positive results were obtained.

\section{Analysis of Outcomes}

Categorical variables were compared with Pearson's chisquared test and continuous variables with the Wilcoxon test (22). Survival, relapse-free survival, and disease-free survival rates were estimated with the Kaplan-Meier method (23). End points were compared using the logrank test.
The Cox proportional hazards model was used to determine the independent effects of study variables. The final model was chosen by a combination of statistical and clinical significance. Statistical considerations included the effect of each variable on the overall model chi-squared statistic and the confounding effects of donor type on each end point. Study variables included age, disease stage, interval from diagnosis to transplant, donor-recipient HLA matching, time-dependent onset of graft versus host disease, graft versus host disease prophylaxis, cytomegalovirus status, and donor-recipient gender match (24). The proportionality assumption of the model was verified. Interactions between donor type and other study variables were also investigated.

Patient follow-up was complete as of September 2000. Infusion of donor lymphocytes after posttransplant hematologic or cytogenetic relapse can lead to return to full donor chimerism without evidence of disease. Therefore, both overall survival and disease-free survival rates are reported. In analysis of disease-free survival, death or hematologic or cytogenetic relapse are scored as events, although some patients returned to full donor chimerism after infusion of donor lymphocytes.

\section{RESULTS}

\section{Survival}

The 5-year survival rate of matched sibling donor bone marrow recipients [58\%; 95\% confidence interval (CI), $48 \%$ to $68 \%$ ] was similar to that of unrelated donor bone marrow recipients (53\%; $95 \% \mathrm{CI}, 39 \%$ to $67 \%$; $P=0.4$; Figure 1). Therefore, risk factors for survival were analyzed within the entire cohort of matched sibling donor and unrelated donor recipients.

Survival at 5 years was similar in recipients younger than 18 years (69\%; $95 \%$ CI, $39 \%$ to $99 \%$ ) and those 18 to 34 years old (68\%; 95\% CI, $50 \%$ to $86 \%$ ), but was significantly lower in those 35 to 56 years old (47\%; 95\% CI, $35 \%$ to $59 \% ; P=0.01)$. Patients who received a transplant less than 1 year after diagnosis had a significantly $(P=0.0001)$ higher 5 -year survival rate $(74 \% ; 95 \% \mathrm{CI}$, $65 \%$ to $83 \%)$ than those who received a transplant 1 to 2 years after diagnosis ( $38 \%$; $95 \% \mathrm{CI}, 19 \%$ to $57 \%$ ) or more than 2 years after diagnosis (24\%; 95\% CI, $4 \%$ to $44 \%$ ) (Figure 2). There was no significant difference $(P=0.5)$ in the 5-year survival rates of matched sibling donor recipients $(76 \%$; $95 \%$ CI, $65 \%$ to $87 \%$ ) and those of unrelated donor recipients (70\%; 95\% CI, 52\% to $88 \%$ ) who underwent transplantation less than 1 year after diagnosis (Figure 3).

The 5-year survival rate was also higher in those receiving a higher marrow cell dose (greater than $2 \times 108 / \mathrm{kg}$ ) ( $65 \%$; $95 \%$ CI, $56 \%$ to $74 \%$ versus $48 \%$; $95 \%$ CI, $65 \%$ to $89 \% ; P=0.04)$ and those who did not develop severe 


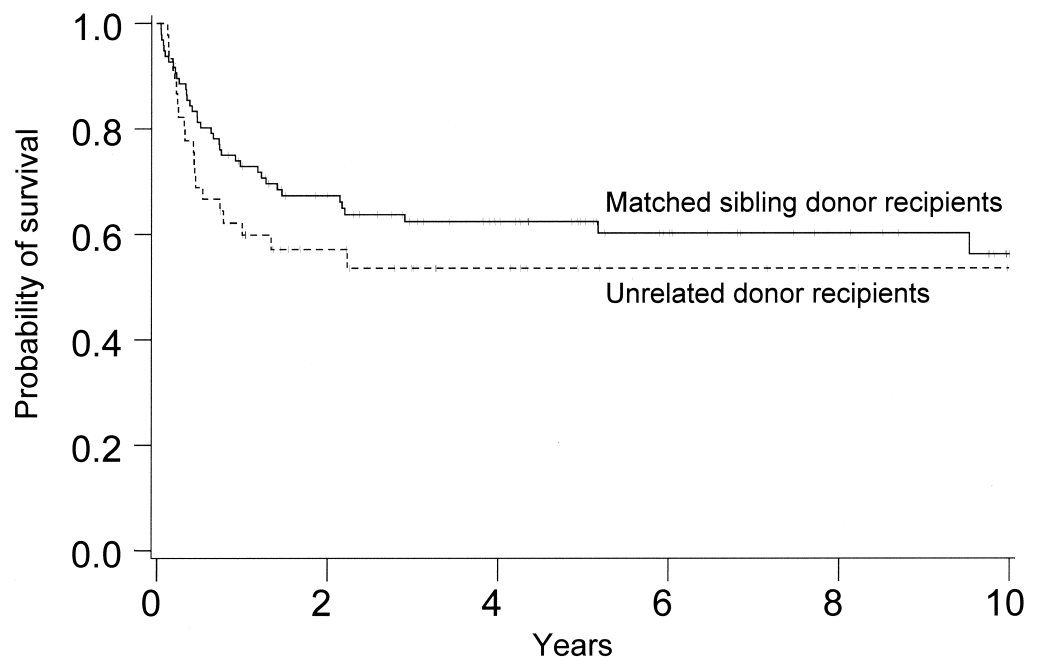

Figure 1. Survival after transplantation of bone marrow from matched sibling donors $(\mathrm{n}=96)$ and from unrelated donors $(\mathrm{n}=45)$ in chronic myelogenous leukemia patients. At 5 years, 32 matched sibling donor recipients and 5 unrelated donor recipients are still alive.

graft versus host disease (65\%; $95 \% \mathrm{CI}, 56 \%$ to $74 \%$ in those with grades 0 to II versus $40 \%$; $95 \%$ CI, $25 \%$ to $64 \% ; P=0.01$ ) in those with grades III and IV]. Male recipients with female donors had a reduced survival rate (39\%; $95 \% \mathrm{CI}, 22 \%$ to $56 \% ; P=0.03$ ), as did recipients of T-cell-depleted marrow, largely because of poor outcomes in matched sibling donor recipients participating in an experimental protocol that was terminated early.

Factors associated with increased mortality in the multiple regression analysis were age younger than 35 years old, transplantation more than 1 year after diagnosis, Tcell-depleted marrow, and grades III to IV graft versus host disease (Table 2). After adjustment for all other vari- ables, the 5-year mortality was not higher in recipients of unrelated donor marrow than in recipients of matched sibling marrow (relative risk 1.1; $95 \% \mathrm{CI}, 0.6$ to $2.1 ; P=$ $0.7)$.

\section{Relapse}

Cytogenetic or hematologic relapse occurred in 21 matched sibling donor recipients (Kaplan-Meier estimate, $29 \%$ at 5 years; $95 \%$ CI, $9 \%$ to $50 \%$ ) and 6 unrelated donor recipients (Kaplan-Meier estimate, 31\%; $95 \%$ CI, $19 \%$ to $44 \% ; P=0.9)$. Twelve of 27 patients who had a relapse received a transfusion of donor lymphocytes; 9 are in a further complete remission, 2 are in com-

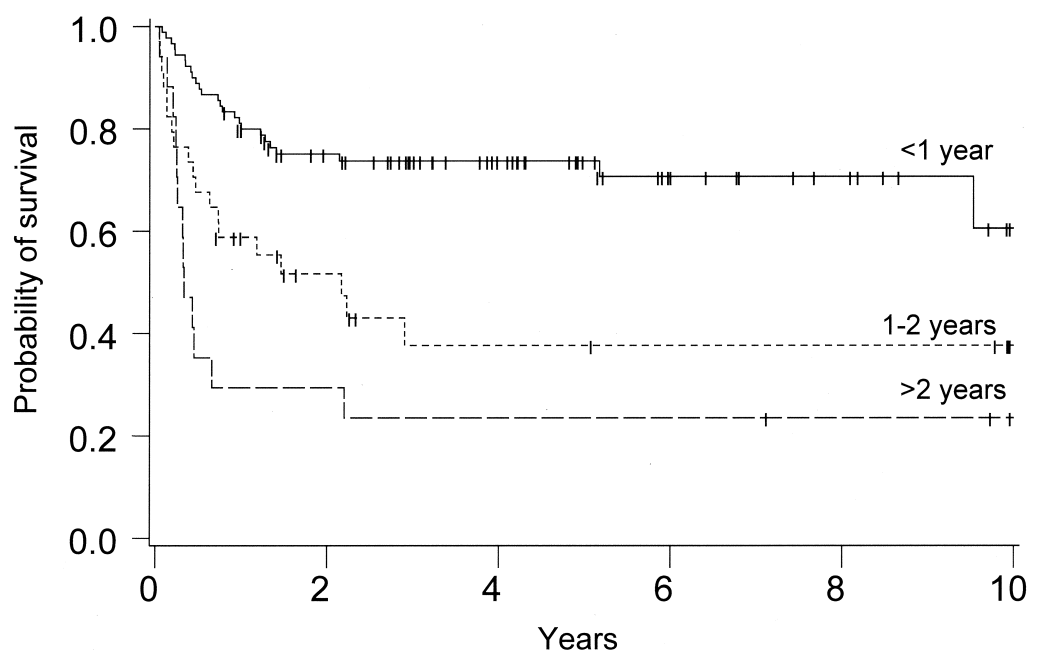

Figure 2. Survival in patients who received a transplant less than 1 year after diagnosis $(\mathrm{n}=90), 1$ to 2 years after diagnosis ( $\mathrm{n}=34$ ), and more than 2 years after diagnosis $(n=17)$. At 5 years, 26 patients who received a transplant less than 1 year after diagnosis, 7 who received a transplant within 1 to 2 years, and 4 who received a transplant more than 2 years after diagnosis are still alive. 


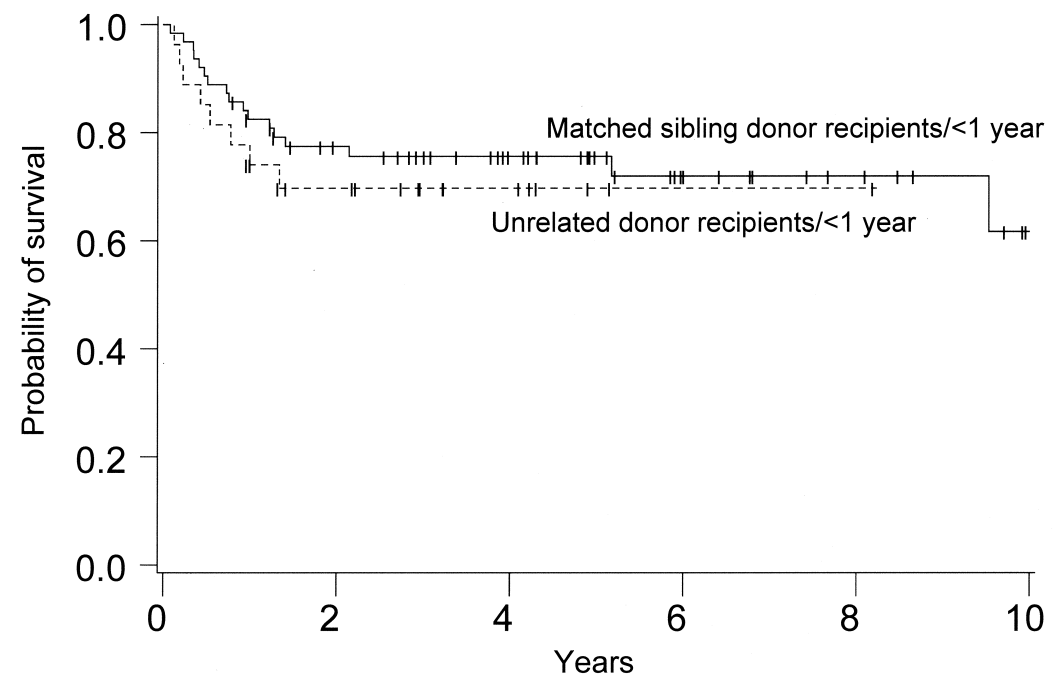

Figure 3. Survival after matched sibling donor $(n=63)$ or unrelated donor $(n=27)$ bone marrow transplant for chronic myelogenous leukemia in patients who received a transplant less than 1 year after diagnosis. At 5 years, 23 matched sibling donor recipients and 4 unrelated donor recipients are still alive.

plete remission after a second bone marrow transplant, and one died without remission. Fifteen patients did not receive transfusion of donor lymphocytes; 5 are in a further complete remission after a second bone marrow transplant, 2 are in complete remission after interferon therapy, 2 have chronic myelogenous leukemia, and 6 died of their disease.

\section{Disease-free Survival}

In univariate analyses, T-cell depletion, transplantation more than 1 year after diagnosis, low cell dose, and grades III and IV graft versus host disease were associated with poorer disease-free survival. The disease-free survival rates were similar after transplantation from an unrelated donor ( $44 \%$; $95 \%$ CI, $34 \%$ to $54 \%$ ) or a matched sibling donor $(42 \%$; $95 \%$ CI, $28 \%$ to $58 \%$; $P=0.6$ ). Delay in transplantation strongly influenced the 5-year diseasefree survival rate, which was $53 \%$ in those who received a transplant in less than 1 year, $30 \%$ in those who received a transplant in 1 to 2 years, and $6 \%$ in those who received

Table 2. Association between Selected Characteristics and 5-Year Mortality: Multivariate Proportional Hazards Model

\begin{tabular}{lcl}
\hline \multicolumn{1}{c}{ Factor } & $\begin{array}{c}\text { Relative Risk } \\
\text { (95\% Confidence } \\
\text { Interval) }\end{array}$ & $\begin{array}{c}P \\
\text { Value }\end{array}$ \\
\hline Unrelated donor & $1.1(0.6-2.1)$ & 0.7 \\
Age $\geq 35$ years & $3.3(0.9-11)$ & 0.06 \\
T-cell depletion & $2.5(1.3-4.8)$ & 0.009 \\
Time to transplant 1-2 years* & $2.1(1.2-4.0)$ & 0.01 \\
Time to transplant $>$ 2 years* & $5.8(2.8-12)$ & 0.0001 \\
Graft versus host disease & $2.2(1.2-4.1)$ & 0.01 \\
\hline
\end{tabular}

\footnotetext{
* Compared with $<1$ year.
}

a transplant more than 2 years after diagnosis $(P=$ 0.0001). Among patients who underwent transplantation within 1 year after diagnosis, the disease-free survival rates were similar in recipients of matched sibling and unrelated donor bone marrow (Figure 4). Multiple regression analysis confirmed the adverse effects of delay in bone marrow transplantation and T-cell depletion on disease-free survival (Table 3).

\section{DISCUSSION}

This study shows that equivalent survival can be achieved in patients with chronic myelogenous leukemia who receive matched sibling donor marrow and those receiving unrelated donor marrow. However, we analyzed recipients of marrow that was serologically matched at HLA-A and $-\mathrm{B}$ and molecularly matched at DRB1. Outcomes might not be as favorable in recipients of less wellmatched marrow. Molecular typing at the HLA-A and -B alleles might further improve outcomes.

In early reports of unrelated donor bone marrow transplantation, graft versus host disease, graft failure, and late infections were frequent, and treatment-related mortality was common (6-8). Our findings in this study are consistent with recent reports of improved outcomes in patients who receive unrelated donor marrow $(25,26)$. Hansen et al (25) reported a 5-year survival rate of $57 \%$ in patients with early-phase chronic myelogenous leukemia; survival was reduced in those who underwent transplantation more than 1 year after diagnosis, received DRB1-mismatched marrow, had a high body-weight index, or were older than 50 years. As in our study, these results were similar to those obtained with matched sib- 


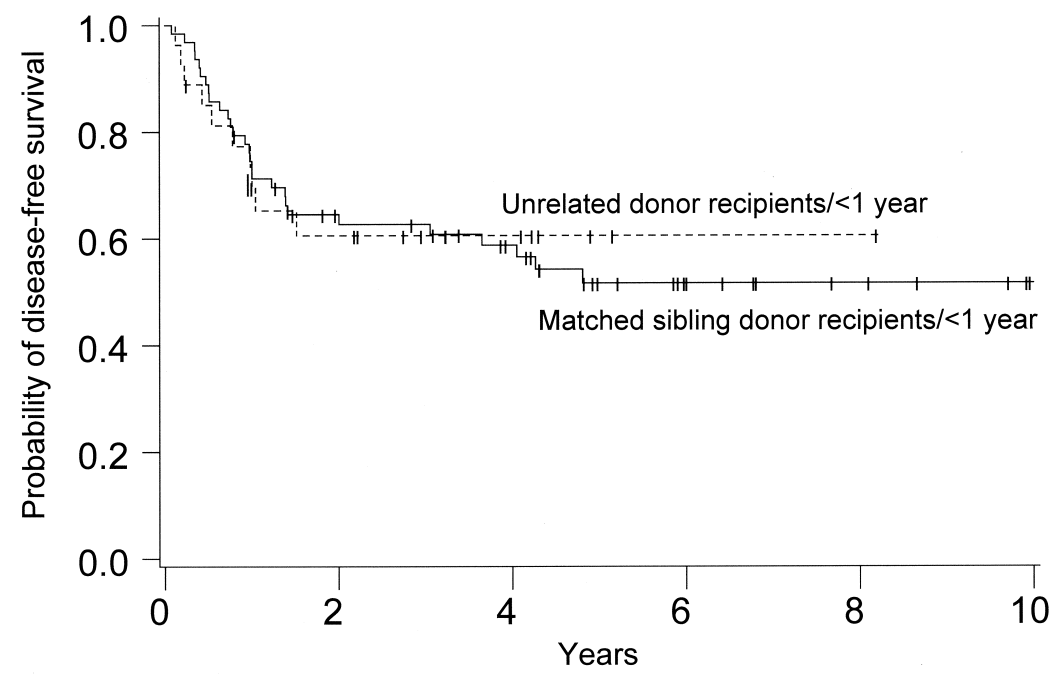

Figure 4. Disease-free survival in patients who received bone marrow from a matched sibling donor $(\mathrm{n}=63)$ or unrelated donor $(\mathrm{n}=27)$ within 1 year of diagnosis. At 5 years, 18 matched sibling donor and 3 unrelated donor recipients are still alive.

ling donors. Dini et al (26) reported survival of $64 \%$ at 4 years in 30 patients with chronic myelogenous leukemia who received a transplant after 1993; survival was reduced in patients who received HLA-mismatched marrow, did not receive radiation therapy, or were treated with cyclosporine before transplantation. Transplantation within 1 year after diagnosis did not influence survival, perhaps, as the authors suggested, because most of the transplants were performed more than 1 year after diagnosis. In our study and in others, transplantation more than 1 year after diagnosis strongly influenced survival in recipients of unrelated donor marrow as well as in recipients of matched sibling donor marrow $(2,27,28)$. As in the study of Hansen et al, older recipient age adversely affected outcome in the present study.

Severe graft versus host disease was associated with reduced survival in our patients. Previous studies of unrelated donor and matched sibling donor transplants for chronic myelogenous leukemia have shown reduced relapse rates in patients with graft versus host disease and in

Table 3. Associations between Selected Characteristics and Disease-free Survival: Multivariate Proportional Hazards Model

\begin{tabular}{lcl}
\hline \multicolumn{1}{c}{ Factor } & $\begin{array}{c}\text { Relative Risk } \\
\text { (95\% Confidence } \\
\text { Interval) }\end{array}$ & $\begin{array}{c}P \\
\text { Value }\end{array}$ \\
\hline Unrelated donor & $0.8(0.5-1.5)$ & 0.5 \\
Age $\geq 35$ years & $1.6(0.9-2.6)$ & 0.06 \\
T-cell depletion & $3.3(1.7-6.2)$ & 0.0003 \\
Time to transplant $1-2$ years & \\
Time to transplant $>$ 2 years & $2.1(1.2-3.5)$ & 0.005 \\
& $5.3(2.9-9.7)$ & 0.0001 \\
\hline
\end{tabular}

\footnotetext{
${ }^{\star}$ Compared with $<1$ year.
}

unrelated donor recipients compared with matched sibling donor recipients, likely because of a graft versus leukemia effect $(27,29)$. Despite any potential graft versus leukemia effect, severe graft versus host disease markedly increased mortality in our patients, indicating the need for improved prophylaxis. T-cell depletion also reduced survival, largely reflecting the excessive mortality in a small cohort of matched sibling donor recipients of Tcell-depleted marrow. An ongoing national randomized study of T-cell depletion in unrelated donor bone marrow transplantation will more clearly address the role of graft versus host disease prophylaxis in recipients of unrelated donor bone marrow, including those with early chronic myelogenous leukemia.

Transplantation of phenotypically matched marrow yielded excellent results. Studies from our center and others have demonstrated the adverse effect of HLA mismatch on outcome. The availability of over 6 million potential bone marrow donors through a web-based bone marrow search tool (Bone Marrow Donors Worldwide, 1998) increases the likelihood of identifying a wellmatched donor. The likelihood of identifying at least one 6-antigen-matched potential donor in a preliminary search of the National Marrow Donor Program is greater than 75\% (National Marrow Donor Program, personal communication, 1998). This still leaves many patients, especially those from minority ethnic and racial groups, without a potential donor. Continuing efforts to diversify the HLA phenotypes in bone marrow registries are important for increasing the availability of suitable bone marrow donors. An alternative strategy for increasing donor availability is to use umbilical cord blood. Although cord blood can be an excellent source of stem cells for young recipients, the small number of stem cells and the 
reduced rates of engraftment limit the immediate applicability of this approach in adults with chronic myelogenous leukemia (30). Ex vivo expansion of stem cells may improve engraftment in these patients.

Patients with chronic myelogenous leukemia can enjoy excellent quality of life, sometimes for years after diagnosis, and the decision to proceed to unrelated donor bone marrow transplantation can be difficult for both patients and physicians. A decision analysis based on data from the National Marrow Donor Program and International Bone Marrow Transplant Registry, including patient age, quality of life, risk aversion, and competing risks of disease progression and transplant toxicity, supports the use of early unrelated donor bone marrow transplantation for most patients with chronic myelogenous leukemia (31). However, these analyses were performed before the tyrosine kinase inhibitor STI 571 became available. The role of this important new agent in the treatment of chronic myelogenous leukemia is currently unknown (32).

STI 571 is an oral agent designed to inhibit the Bcr-Abl transcript produced by the Philadelphia chromosome that is characteristic of chronic myelogenous leukemia. Treatment with STI 571 has led to complete cytogenetic responses in some patients with chronic myelogenous leukemia in the chronic or accelerated phase and in some patients with resistant or refractory disease, with little toxicity (32-34). However, the frequency of responses is modest in some groups of patients $(9 \%$ in the accelerated phase and $13 \%$ in the resistant disease), and the duration of response is unknown $(33,34)$. Because chronic myelogenous leukemia progresses slowly, it will be some years before it is apparent whether any patients treated with STI 571 are cured of their disease. We recommend that patients with newly diagnosed chronic myelogenous leukemia search aggressively for an unrelated donor and, if a donor is identified, undergo bone marrow transplantation without delay.

\section{REFERENCES}

1. Goldman JM, Apperley JF, Jones L, et al. Bone marrow transplantation for patients with chronic myeloid leukemia. $N$ Engl J Med. 1986;314:202-207.

2. Thomas ED, Clift RA, Fefer A, et al. Marrow transplantation for the treatment of chronic myelogenous leukemia. Ann Intern Med. 1986;104:155-163.

3. Thomas ED, Clift RA. Indications for marrow transplantation in chronic myelogenous leukemia. Blood. 1989;73:861-864.

4. Perkins HA, Hansen JA. The U.S. National Marrow Donor Program. Am J Ped Hematol Oncol. 1994;16:30-34.

5. Confer DL. Unrelated donor marrow registries. Curr Opin Hematol. 1997;4:408-412.

6. Kernan NA, Bartsch G, Ash RC, et al. Analysis of 462 transplantations from unrelated donors facilitated by the National Marrow Donor Program. N Engl J Med. 1993;328:593-602.

7. Davies SM, Ramsay NKC, Haake RJ, et al. Comparison of engraft- ment in recipients of matched sibling or unrelated donor marrow allografts. Bone Marrow Transplant. 1994;13:51-57.

8. Ochs L, Shu XO, Miller J, et al. Late infections after allogeneic bone marrow transplantations: comparison of incidence in related and unrelated donor transplant recipients. Blood. 1995;86:3979-3986.

9. Hehlmann R, Heimpel H, Hasford J, et al. Randomized comparison of interferon-alpha with busulfan and hydroxyurea in chronic myelogenous leukemia. The German CML Study Group. Blood. 1994; 84:4064-4077.

10. The Italian Cooperative Study Group in Chronic Myeloid Leukemia. Interferon alfa-2a as compared with conventional chemotherapy for the treatment of chronic myeloid leukemia. $N$ Engl J Med. 1994;330:820-825.

11. Hasford J, Baccarani M, Hehlmann R, et al. Interferon-alpha, and hydroxyurea in early chronic myeloid leukemia. A comparative analysis of the Italian and German chronic myeloid leukemia trials with interferon-alpha. Blood. 1996;87:5384-5391.

12. Chronic Myeloid Leukemia Trialists' Collaborative Group. Interferon alpha versus chemotherapy for chronic myeloid leukemia: a meta-analysis of seven randomized trials. J Natl Cancer Inst. 1997; 89:1616-1620.

13. Ohnishi K, Tomonaga M, Kamada N, et al. A long-term follow-up of a randomized trial comparing interferon-alpha with busulfan for chronic myelogenous leukemia. The Kouseisho Leukemia Study Group. Leuk Res. 1998;22:779-786.

14. Kantarjian HM, Smith TL, O'Brien S, et al. Prolonged survival in chronic myelogenous leukemia after cytogenetic response to interferon-alpha therapy. The Leukemia Service. Ann Intern Med. 1995; 122:254-261.

15. Allen NC, Richards SM, Shepherd PC. UK Medical Research Council randomised, multicentre trial of interferon-alpha for chronic myeloid leukaemia: improved survival irrespective of cytogenetic response. The UK Medical Research Council's Working Parties for Therapeutic Trials in Adult Leukaemia. Lancet. 1995;345:13921397.

16. Giralt SA, Kantarjian HM, Talpaz M, et al. Effect of prior interferon alfa therapy on the outcome of allogeneic bone marrow transplantation for chronic myelogenous leukemia. J Clin Oncol. 1993;11: 1055-1061.

17. Beelen DW, Graeven U, Elmaagacli AH, et al. Prolonged administration of interferon-alpha in patients with chronic-phase Philadelphia chromosome-positive chronic myelogenous leukemia before allogeneic bone marrow transplantation may adversely affect transplant outcome. Blood. 1995;85:2981-2990.

18. Morton AJ, Gooley T, Hansen JA, et al. Association between pretransplant interferon-alpha and outcome after unrelated donor marrow transplantation for chronic myelogenous leukemia in chronic phase. Blood. 1998;92:394-401.

19. Davies SM, Shu XO, Blazar BR, et al. Unrelated donor bone marrow transplantation: influence of HLA A and B incompatibility on outcome. Blood. 1995;86:1636-1642.

20. Filipovich AH, Vallera DA, Youle RJ, et al. Graft-versus-host disease prevention in allogeneic bone marrow transplantation from histocompatible siblings. A pilot study using immunotoxins for $\mathrm{T}$ cell depletion of donor bone marrow. Transplantation. 1997;44:6269.

21. Wagner JE, Santos GW, Noga SJ, et al. Bone marrow graft engineering by counterflow centrifugal elutriation: results of a phase I-II clinical trial. Blood. 1990;75:1370-1377.

22. Snedecor G, Cochran W. Statistical Methods, 8th ed. Ames, IA: Iowa State University Press, 1989.

23. Kaplan EL, Meier P. Non-parametric estimation from incomplete observations. J Am Stat Assoc. 1958;53:457-481.

24. Cox DR. Regression models and life tables. J Roy Stat Soc B. 1972; 34:187-220. 
25. Hansen JA, Gooley TA, Martin PJ, et al. Bone marrow transplants from unrelated donors for patients with chronic myeloid leukemia. N Engl J Med. 1998;338:962-968.

26. Dini G, Lamparelli T, Rondelli R, et al. Unrelated donor marrow transplantation for chronic myelogenous leukaemia. Br J Haematol. 1998;102:544-552.

27. Enright H, Daniels K, Arthur DC, et al. Related donor marrow transplant for chronic myeloid leukemia: patient characteristics predictive of outcome. Bone Marrow Transplant. 1996;17:537-542.

28. Appelbaum FR, Clift R, Radich J, Anasetti C, Buckner CD. Bone marrow transplantation for chronic myelogenous leukemia. Semin Oncol. 1995;22:405-411.

29. Hessner MJ, Endean DJ, Casper JT, et al. Use of unrelated marrow grafts compensates for reduced graft-versus-leukemia reactivity after T-cell-depleted allogeneic marrow transplantation for chronic myelogenous leukemia. Blood. 1995;86:3987-3996.
30. Kurtzberg J, Laughlin M, Graham ML, et al. Placental blood as a source of hematopoietic stem cells for transplantation into unrelated recipients. N Engl J Med. 1996;335:157-166.

31. Lee SJ, Kuntz KM, Horowitz MM, et al. Unrelated donor bone marrow transplantation for chronic myelogenous leukemia: a decision analysis. Ann Intern Med. 1997;127:1080-1088.

32. Druker BJ, Talpaz M, Resta D, et al. Clinical efficacy and safety of an ABL specific tyrosine kinase inhibitor as targeted therapy for chronic myelogenous leukemia. Blood. 1999;94:368A.

33. Talpaz M, Silver RT, Druker B, et al. A phase II study of STI 571 in adult patients with Philadelphia chromosome positive chronic myeloid leukemia in accelerated phase. Blood. 2000;96:469A.

34. Kantarjian H, Sawyers C, Hochhaus A, et al. Phase II study of STI 57I, a tyrosine kinase inhibitor, in patients with resistant or refractory Philadelphia chromosome positive chronic myeloid leukemia (Ph + CML). Blood. 2000;96:470A. 